\title{
Editorial
}

Digestion

\section{latrogenic Colonoscopic Perforations: Clipping or Calling for a Surgeon?}

\author{
Romain Coriat ${ }^{a, b}$ Wulfran Cacheux ${ }^{a, b}$ Stanislas Chaussade ${ }^{a, b}$ \\ ${ }^{\mathrm{a}}$ Gastroenterology and Endoscopy Unit, CHU Cochin, and baculté René Descartes, Paris, France
}

Colonoscopic perforation has become one of the most fearsome complications of routine or therapeutic gastrointestinal endoscopy. Usually, the management of colonoscopic perforations requires surgery. In the current issue, Kang et al. [1] report the incidence and medical management of colonoscopic perforations in Korea. Perforations of the colon may occur due to mechanical or thermal injuries secondary to the sectional coagulation of polyps. Management of perforations after diagnostic or therapeutic colonoscopy is controversial. Perforation rates were $0.12 \%$ in the Korean study, but it includes a large number of rectosigmoidoscopies, which are a less risky procedure. Colonoscopic perforations occurred in $0.01 \%$ of patients undergoing screening colonoscopy [2] It is known that perforation risk is greatest for the sigmoid colon, presumably due to the bending of the sigmoid. Polypectomy in the right colon and especially on the ileocaecal valve is technically more difficult and leads to more complications [3]. Major complications such as perforation and haemorrhage occur 2.4 times more often in the right than in the left colon during therapeutic endoscopy [4]. The current incidence of perforation is low but has increased within the past years with the wide use of new endoscopic techniques necessary to remove large polyps $(>2 \mathrm{~cm})$. New endoscopic procedures, such as endoscopic submucosal dissection (ESD) techniques, have been used initially for superficial lesions in the stomach by Japanese endoscopists [5]. This technique has been secondarily applied to colorectal polyps. Submucosal in- cision with an electrosurgical knife is performed until the tumor is completely resected in one piece. ESD in the colon is difficult. The difficulty is due to the unsuitable anatomical characteristics of the colon (thin wall and existence of peristalsis, folds and flexions) [6]. The rate of perforation markedly decreased with the wider practice of ESD [7]. Colonoscopic polypectomy is associated with a $1-10 \%$ complication rate $[4,8]$. More than $90 \%$ of those complications can be managed conservatively with endoscopic therapy.

Treatment strategy ranges from non-operative management to open colonic diversion. In the Korean study, it is reported that $36 \%$ of the patients were managed conservatively. Nine patients underwent endoscopic perforation closure using hemoclips. Twenty-nine percent of those patients underwent colonic resection with anastomosis. In a retrospective review of laparoscopic repair of colonic perforations, the mean colonic perforation size was $2.7 \mathrm{~cm}$ [9]. In order to avoid surgery, endoscopic repair has been proposed. Two types of perforation can occur. The first type is associated with polypectomy, endoscopic mucosal resection or ESD. In this situation, the perforation defect is not very large and the endoscopic closure with clips is very efficient. After diagnostic procedures, colonoscopic perforations generally occur in the sigmoid. Sigmoids represent up to $65 \%$ of the colonic perforations in the Korean study. In these cases, surgery is the preferred technique because the perforation defect is often very large, and complete clipping of this defect can

\section{KARGER}

Fax +4161306 1234 E-Mail karger@karger.ch www.karger.com
(C) 2009 S. Karger AG, Basel 0012-2823/08/0784-0214\$24.50/0

Accessible online at: www.karger.com/dig

\section{Romain Coriat}

Gastroenterology and Endoscopy Unit, CHU Cochin

27, rue du Faubourg St. Jacques

FR-75014 Paris (France)

Tel. +33 15841 1901, Fax +33 15841 1930,E-Mail romain.coriat@cch.aphp.fr 
also be difficult. Clipping must be done immediately when colonic perforation is recognized. In the study by Kang et al. [1], a complete closure of the perforation was attempted and a mean number of 4.8 clips per patient was used.

Patients should be aware and informed of the endoscopic risk. Management of colonoscopic perforation has to be done with a large number of clips to close the entire hole. Conservative management should also include all non-operative forms of medical management (withholding of oral intake, hydration intravenous antibiotics).

Management of colonic perforation should be undertaken with a conservative attitude if possible. If not, laparotomy is the second best option.

\section{References}

1 Kang HY, Kang HW, Kim SG, Kim JS, Park KL, Jung HC, Song IS: Incidence and management of colonoscopic perforations in Korea. Digestion, in press.

2 Niv Y, Hazazi R, Levi Z, Fraser G: Screening colonoscopy for colorectal cancer in asymptomatic people: a meta-analysis. Dig Dis Sci 2008, Epub ahead of print.

3 Church JM: Experience in the endoscopic management of large colonic polyps. ANZ J Surg 2003;73:988-995.
Heldwein W, Dollhopf M, Rosch T, Meining A, Schmidtsdorff G, Hasford J, Hermanek P Burlefinger R, Birkner B, Schmitt W: The Munich Polypectomy Study (MUPS): prospective analysis of complications and risk factors in 4,000 colonic snare polypectomies. Endoscopy 2005;37:1116-1122.

5 Tanaka M, Ono H, Hasuike N, Takizawa K: Endoscopic submucosal dissection of early gastric cancer. Digestion 2008;77(suppl 1): 23-28.

6 Fujishiro M, Yahagi N, Kakushima N, Kodashima S, Muraki Y, Ono S, Yamamichi N, Tateishi A, Oka M, Ogura K, Kawabe T, Ichinose M, Omata M: Outcomes of endoscopic submucosal dissection for colorectal epithelial neoplasms in 200 consecutive cases. Clin Gastroenterol Hepatol 2007;5:678-683; quiz 645.
Tanaka S, Oka S, Kaneko I, Hirata M, Mouri R, Kanao H, Yoshida S, Chayama K: Endoscopic submucosal dissection for colorectal neoplasia: possibility of standardization. Gastrointest Endosc 2007;66:100-107.

8 Kofman T, Coriat R, Chaput U, Gaudric M, Prat F, Brezault C, Grandjouan S, Chaussade S: Quelle est la morbi-mortalité des mucosectomies endoscopiques dans un centre de référence? Etude sur 103 mucosectomies. Gastroenterol Clin Biol 2008;32:A68.

-9 Hansen AJ, Tessier DJ, Anderson ML, Schlinkert RT: Laparoscopic repair of colonoscopic perforations: indications and guidelines. J Gastrointest Surg 2007;11:655659. 